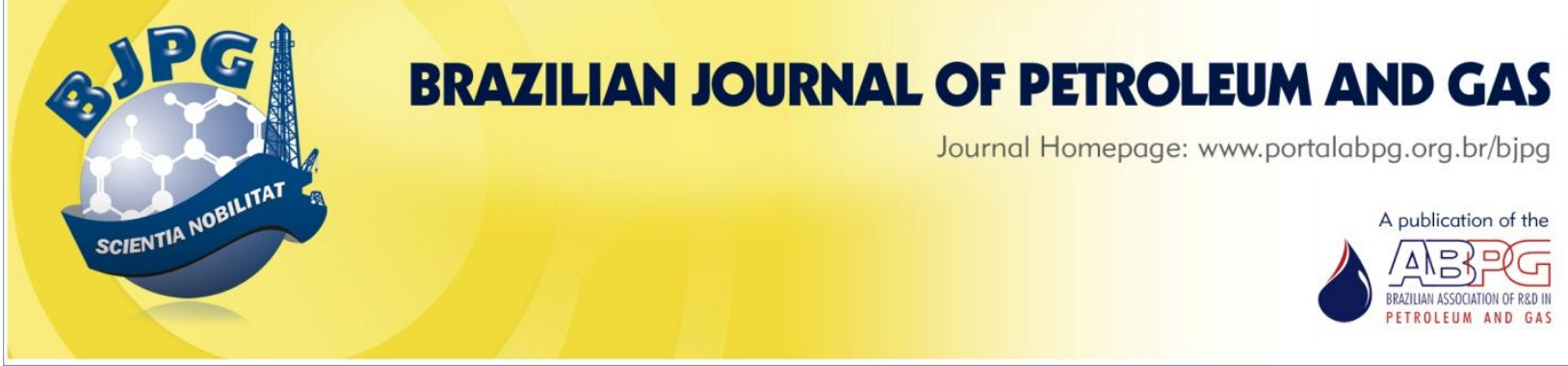

\title{
OPTIMIZATION OF CHARACTERISTIC PROPERTIES OF FOAM-BASED DRILLING FLUIDS
}

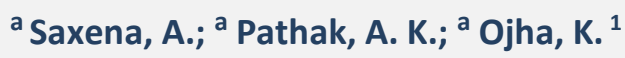 \\ ${ }^{a}$ Department of Petroleum Engineering, Indian School of Mines, Dhanbad, India
}

\begin{abstract}
In recent times, drillers all over the world are encountering highly fractured or matured reservoirs. Conventional drilling techniques are failing to drill efficiently and economically, causing problems of formation damage, lost circulation etc. With increasing energy demands, the industry requires to develop new techniques that can exploit these formations effectively and minimize the problems associated with conventional drilling. In-depth investigations over the years established that underbalanced drilling with foam fluid could be one of the best possible solutions for efficient production from these reservoirs. They have high viscosity and high cutting carrying capability with unusually low density. However, little is known about their rheology, stability and hydrodynamics in dynamic bottomhole conditions, rendering their use difficult in drilling operations. The present work focused on the study of various rheological and stabilization aspects of foam-based drilling fluids for different surfactant and polymer combinations. An optimized combination was predicted for surfactants and polymers which helps in the modeling of different foam hydraulics parameters of the drilling fluids.
\end{abstract}

\section{KEYWORDS}

foam; polymer; surfactant; drilling fluid; stability; viscosity; optimization

\footnotetext{
${ }^{1}$ To whom all correspondence should be addressed.

Address: Department of Petroleum Engineering, Indian School of Mines, Dhanbad, India

Telephone: +91 326-2235484 |e-mail: keka_ojha@yahoo.com; amitsaxenaism@gmail.com; akhilendra pathak@yahoo.co.in doi:10.5419/bjpg2014-0005
} 


\section{INTRODUCTION}

Special physical characteristics of aqueous foams render them excellent candidates as drilling fluids for geothermal formations and coalbed methane reservoirs, as well as those that are highly sensitive towards formation damage. Aerated drilling fluids are being used in drilling technology since the mid of 1930s, though the first engineering discussions on an aerated drilling mud was published in 1953 (Bobo \& Barrett, 1953). According to Negrao et al. (1999), Ozbayoglu et al. (2002) and Saintpere et al. (1999), aqueous foam, which is a special class of aerated fluid, has been used in drilling operations since 1975. Foam, which is a cluster of gas bubbles dispersed in a liquid continuum, is comprised of water or brine and surface-active agents, i.e. surfactants. Foam fluids generally consist of 5-40\% of the liquid phase and 95-60\% of the gaseous phase. Edrisi (2012) observed that addition of various additives such as polymers, gels and other chemicals to the system can enhance its properties and stability.

According to Negrao et al. (1999), foam-based drilling fluids are capable of mitigating various problems encountered in matured and fractured reservoirs, like formation damage and lost circulation, which is otherwise very difficult by using conventional techniques. Foam drilling fluids can also prevent differential sticking and can enhance the hydrocarbon production rates by alleviating the near wellbore formation damage. High viscosity combined with characteristically low density makes the foam as an inevitable candidate for today's complex drilling operations. Because of these exceptional properties, foam could promote good cutting transport with increased rate of penetration and decreased fluid loss (Bonilla et al., 2000; Darley, 2011; Machado \& Ikoku, 1982; Wan, 2010). Foam is a non-Newtonian pseudo-plastic fluid and its viscosity is much higher than the viscosity of its individual constituents (Herzhafta, 2005). Studies show that its specific gravity usually lies in the range 0.2 to 0.7 (Darley et al., 2011; Wan et al., 2010). Like any other drilling fluids, foam picks up cuttings from the bottom of the hole and transfers them back to the surface through the annulus between drill pipes and the bore hole (Li, 2009). However, the high sensitivity of foam rheology to pressure and temperature conditions and its compressible nature makes the job difficult and unpredictable.
Thus, knowledge of rheology is the key to control the entire drilling operations (Sanghani, 1983; Weaire, 2008), and becomes the main constraint behind its restricted utilization. According to Darley (2011), a number of rheological models have also been developed by many investigators. However, these models are very much system-specific and thus unable to describe general foam rheology accurately. The proposed investigation focuses on the rheological behaviors of foams composed of various surfactants and polymers in the presence of salts. Various parameters like viscosity, gel strength, foam stability and behavior index have been studied in detail.

\section{MATERIALS AND METHODS}

\subsection{Materials}

Different chemicals used for the present investigation were of high purity (> $99.5 \%$ ) and used without further treatment. Anionic surfactant SDS (sodium dodecyl sulfate) was purchased from Fisher Scientific, Mumbai, India. CTAB (Cetyltrimethyl ammonium bromide), which is a cationic surfactant, was purchased from Acros Organic, Geel Belgium. The polymer Hydroxy Ethyl Cellulose (HEC) used in the present study was acquired from Otto Kemi, Mumbai, India.

\subsection{Methods}

\subsubsection{Preparation of foam fluid}

Foam was prepared in $200 \mathrm{~mL}$ of brine solution at varying polymer and surfactant concentrations. First, $1 \%$ (by wt) $\mathrm{KCl}$ was dissolved in distilled water and then the required amount of surfactants and polymers were mixed to this brine solution at predetermined weight. The mixture was then stirred for 5 minutes with the help of a mechanical stirrer at a controlled speed of $200 \mathrm{rpm}$ to make it homogeneous. In the next step, the speed of the stirrer was increased to $4000 \mathrm{rpm}$ and maintained at this level for some time until the desired quality of foam was obtained. According to Gumati (2011), the desired range of the foam quality generally lies within $70 \%$ and $90 \%$. Figure 1 describes the steps of the foam preparation process. The temperature of the system was maintained at $30{ }^{\circ} \mathrm{C}$ for the entire study. 


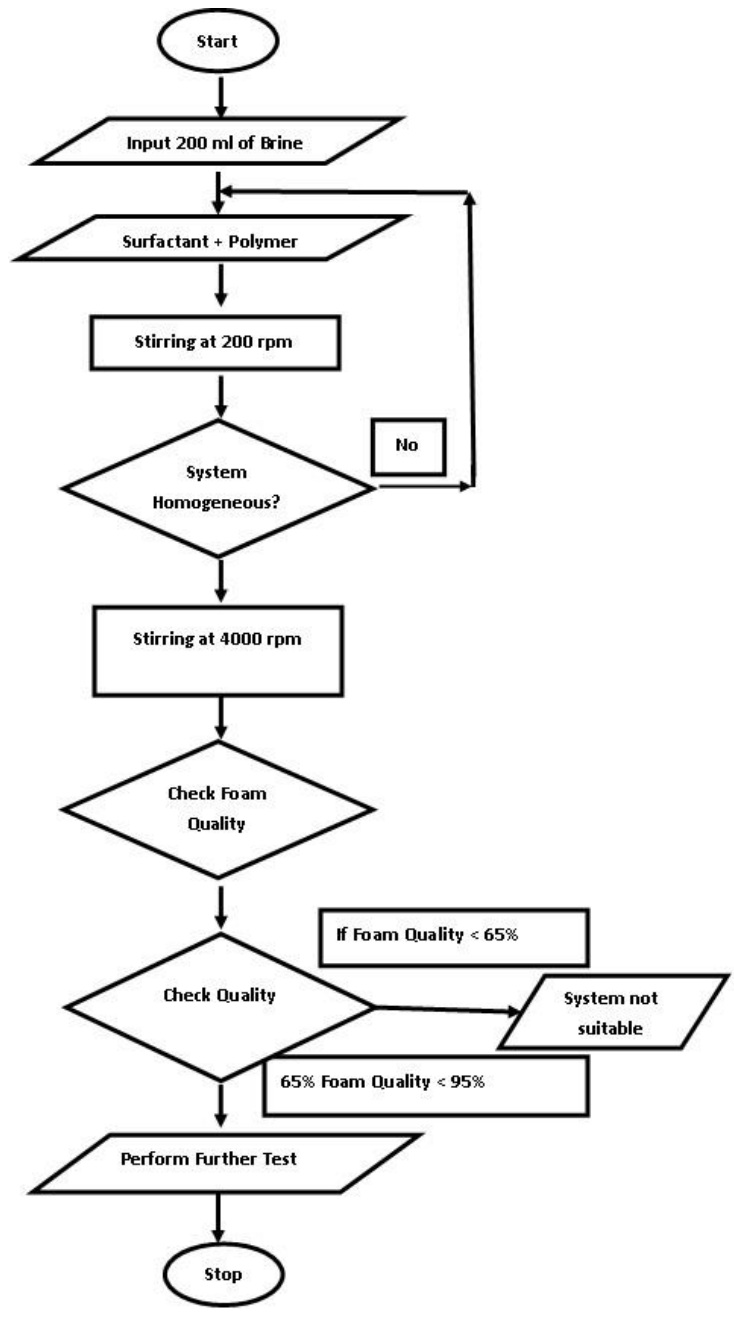

Figure 1. Flowchart for preparation of foam.

\subsubsection{Determination of half-life of foam}

Half-life time, which indicates the stability of foam and hence the working time (Rand, 1983; Tyrode, 2003), was determined by observing the change in height of foam with time. Instantaneously prepared foam was poured in a 1000-mL measuring cylinder which was kept inside a water bath maintained at $30^{\circ} \mathrm{C}$. When exposed to the local atmosphere, the bubbles start to coalesce and the foam-height starts decreasing. The height of the foam was examined continuously and the time at which the foam height was reduced to its half was noted as the half-life time. The thermal stability of foam was also investigated by observing the change of foam quality as a function of temperature.

\subsubsection{Determination of gel strength and viscosity}

A Fann VG viscometer (Model $35 \mathrm{SA}$ ) with the ability to perform assays at six different speeds, ranging from $3 \mathrm{rpm}$ to $600 \mathrm{rpm}$, was used in the determination of foam viscosity and gel strength. To select the desired speed, the switch located on the right side of the base was set to the high or low speed position as desired. Then the motor was turned on and the viscometer gear shift knob located in the centre of the top of the instrument was moved to its desired position. A total of 450 $\mathrm{mL}$ of foam was taken each time for the entire study using this instrument.

Dial readings at $300 \mathrm{rpm}$ and $600 \mathrm{rpm}$ were observed during the determination of apparent viscosity, plastic viscosity, behavior index and consistency index. Gel strengths were measured first by stirring the sample thoroughly at $600 \mathrm{rpm}$ for $30 \mathrm{~s}$, and then by turning off the motor for $10 \mathrm{~s}$. The dial readings were then noted after $10 \mathrm{~s}$ and 10 min while the cylinder speed was kept at $3 \mathrm{rpm}$. The gel strength was reported in $\mathrm{lb} / 100 \mathrm{sq}-\mathrm{ft}$.

\section{RESULTS AND DISCUSSIONS}

Foam stability and rheology are to the two most important properties of foam-based drilling fluids which must be maintained at the desired value within the wellbore during drilling operations. The effects of base fluids compositions, i.e. polymer concentration, surfactant concentrations, and the effect of the ionic characteristics of surfactants and temperature on the foam stability and rheology were studied in detail and reported.

\subsection{Foam stability}

\subsubsection{Effects of polymer and surfactant concentrations on foam stability}

Figures 2-9 describe the foaming ability and foam stability of CTAB and SDS surfactants separately with HEC polymer system. Surfactant concentrations were varied from $0.1 \%$ to $0.4 \%$ by wt. at different polymer dosing starting from 0.10 $\%$ to $0.40 \%$ by wt. The height of the foam just after completion of agitation shows the foaming ability which was characterized by increased height of the foamed slurries. The plots (Figure 2-Figure 9) show 


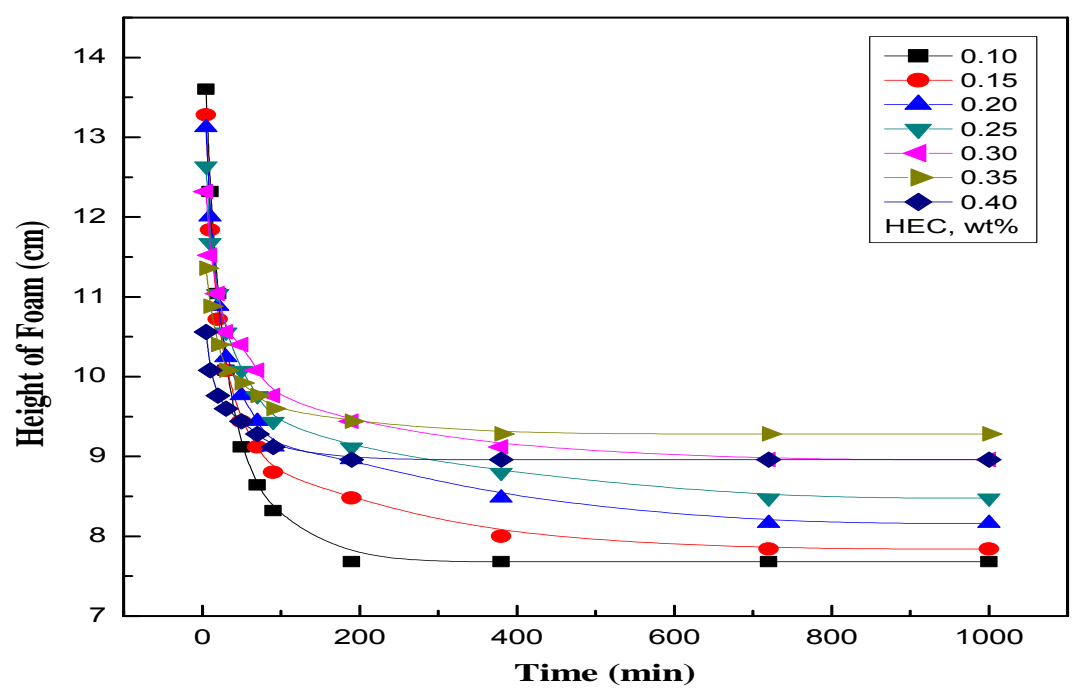

Figure 2. Effect of polymer concentration on foam stability for CTAB (0.1wt.\%).

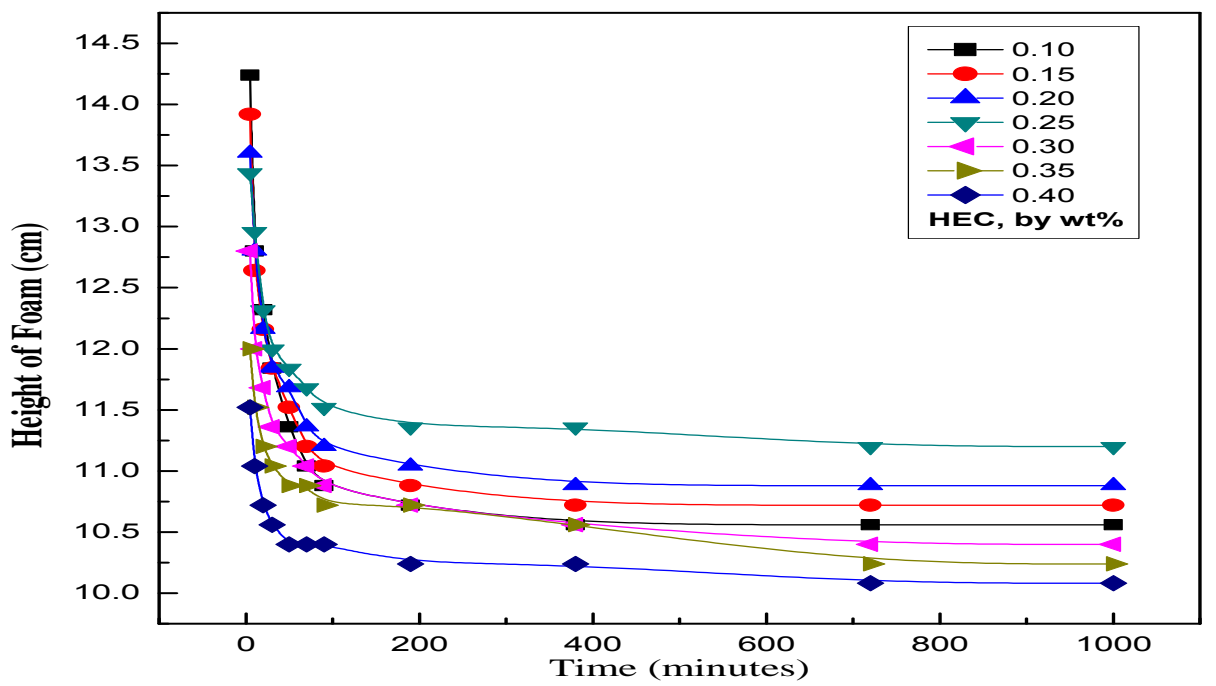

Figure 3. Reduction in height of foam with time at different polymer concentration (0.1 wt. \% SDS).

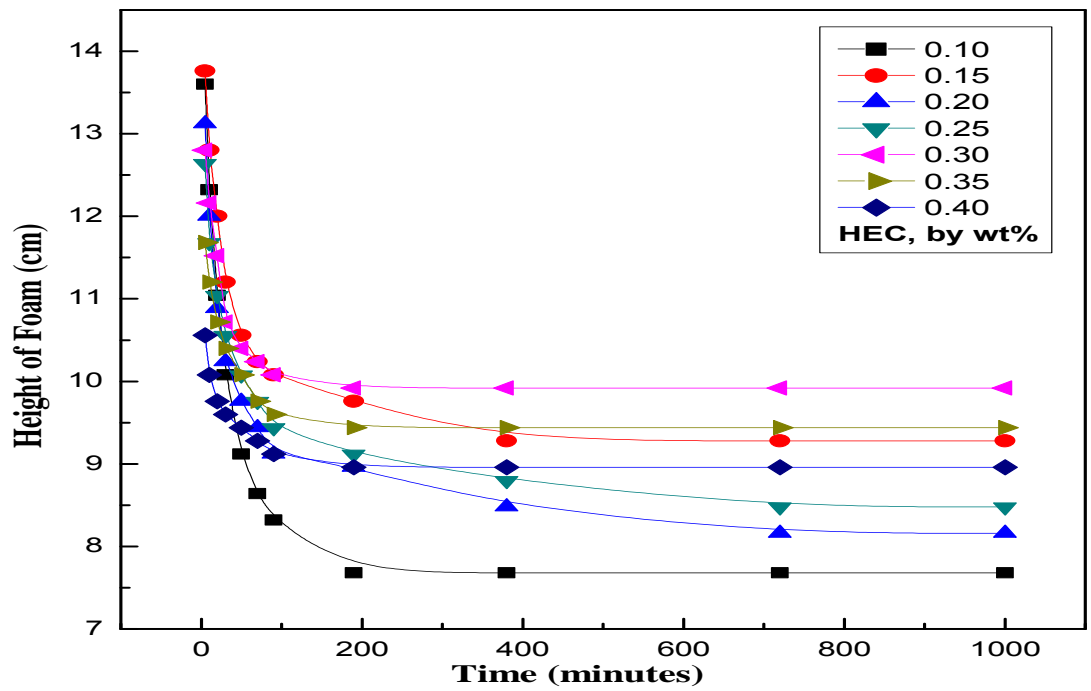

Figure 4. Change in foam stability at varying polymer concentrations for $0.2 \mathrm{wt}$. \% CTAB. 


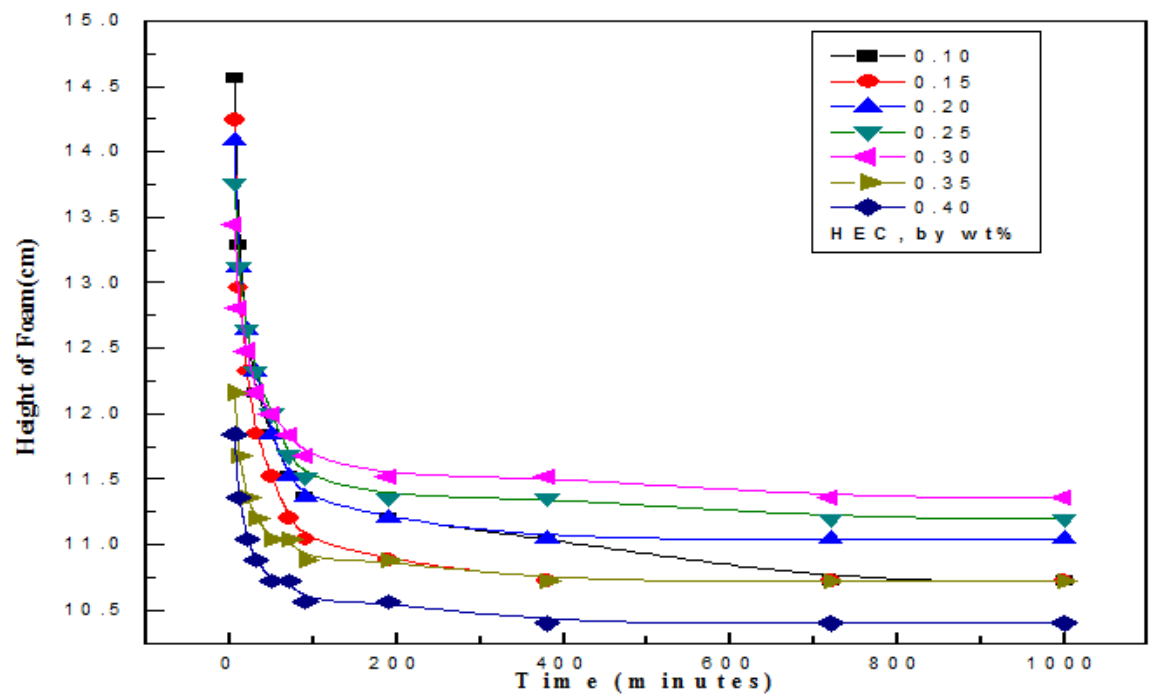

Figure 5. Decrease in foam height for different polymer concentration at 0.2 wt. \% SDS.

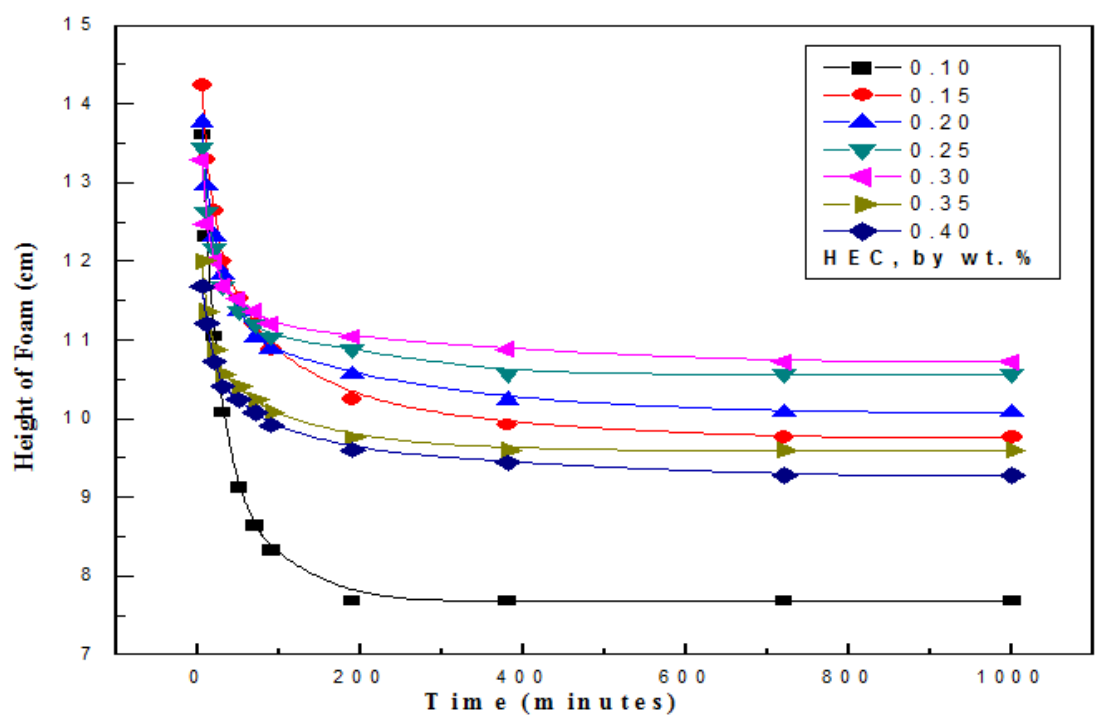

Figure 6. Change in foam Stability at varying polymer concentrations for 0.3 wt. \% CTAB.

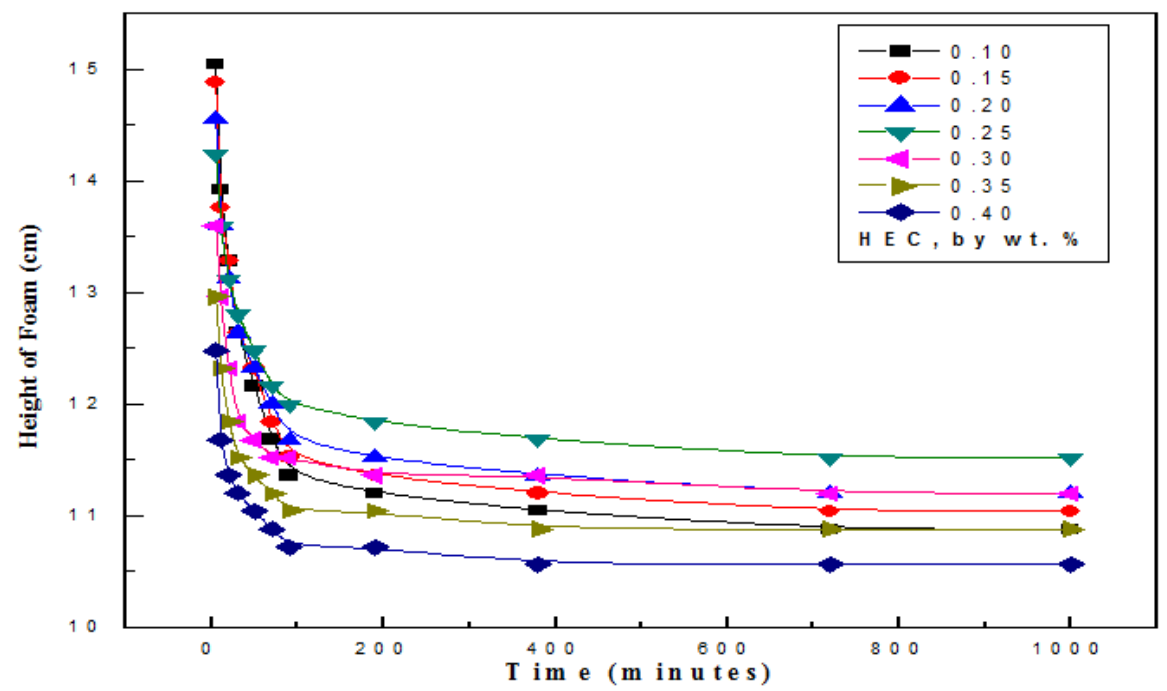

Figure 7. Reduction in height of foam at for different polymer concentration at $0.3 \mathrm{wt}$ \% SDS. 


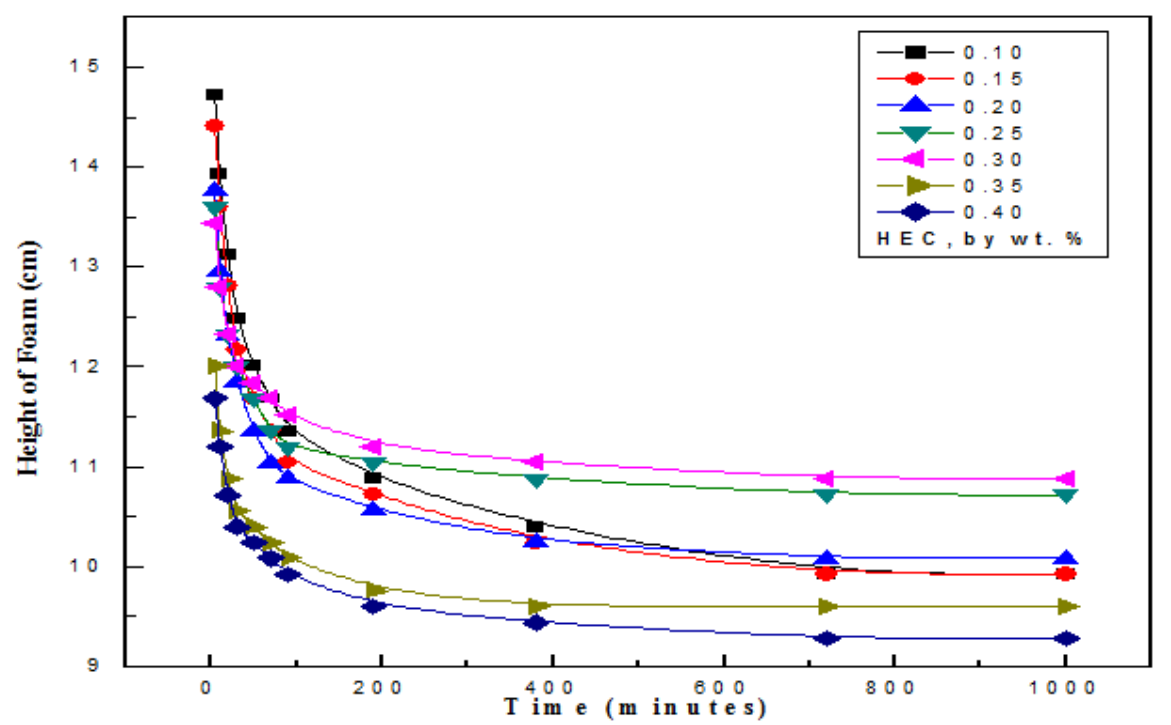

Figure 8. Effect of polymer concentration on foam stability for 0.4 wt. \% CTAB.

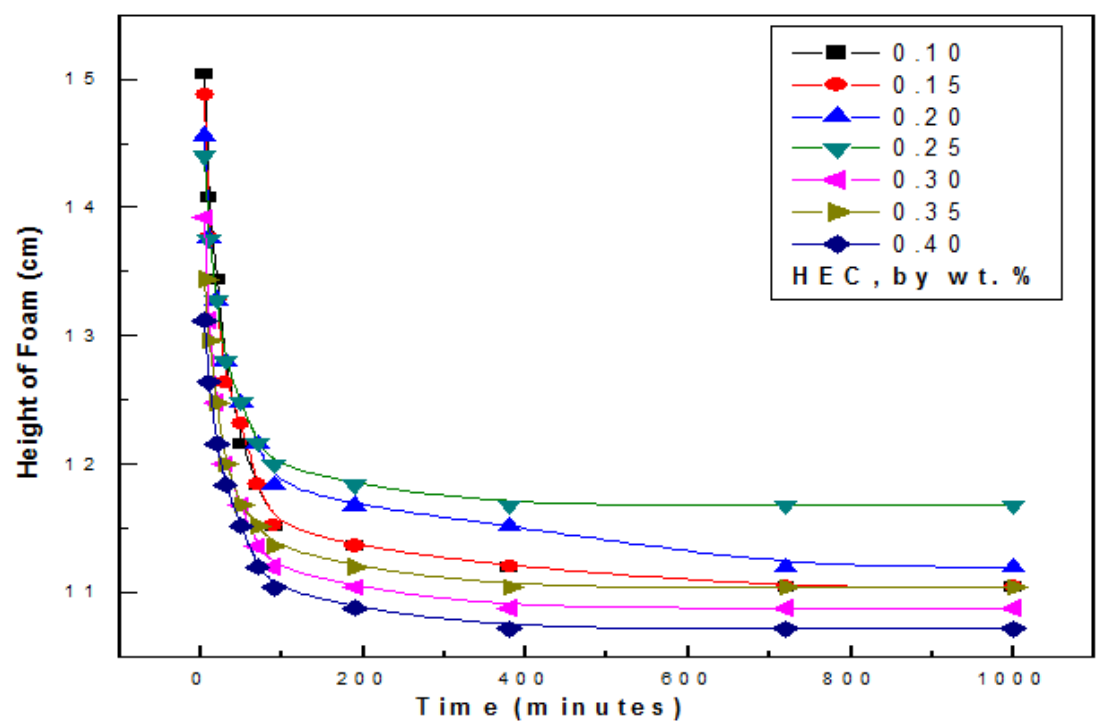

Figure 9. Effect of polymer concentration on foam stability (0.4 wt. \% SDS).

continuous reduction in foam height as a function of idle time after the foaming process. The foams collapse with time, causing decrease in height. It could be observed from Figure 2 that there is reduction of foam height of about $54 \%$ and $84 \%$ after 190 minutes for HEC concentrations of $0.1 \%$ and $0.3 \%$ respectively, which remained almost the same up to $1000 \mathrm{~min}$. However, in the case of SDS, Figure 3 shows a reduction of $74 \%$ and $83.3 \%$ of the initial foam height at HEC concentrations of 0.1 $\%$ and $0.25 \%$ respectively, which then became stable. For both surfactants, foam quality and stability were found to be enhanced with increased HEC concentrations up to an optimum value and then started to fall. Similar results were observed for different CTAB and HEC concentrations as shown in Figures 4-9. The higher foaming capability of SDS compared to CTAB may be due to better binding of polymer unto the head group region of SDS clusters (Winnik and Winnik, 1990). Similar results were also observed by Tyrode et al.(2003) and Wang and co-workers (2012).

According to Edrisi (2012), addition of polymer increases the mechanical strength of the bubble film, thereby reducing fluid drainage. However, the presence of excess polymer may impair foam formation, thereby causing reduction in foam quality. After observing the plots of different surfactant and polymer concentrations it could be inferred that the optimized compositions are 0.4 


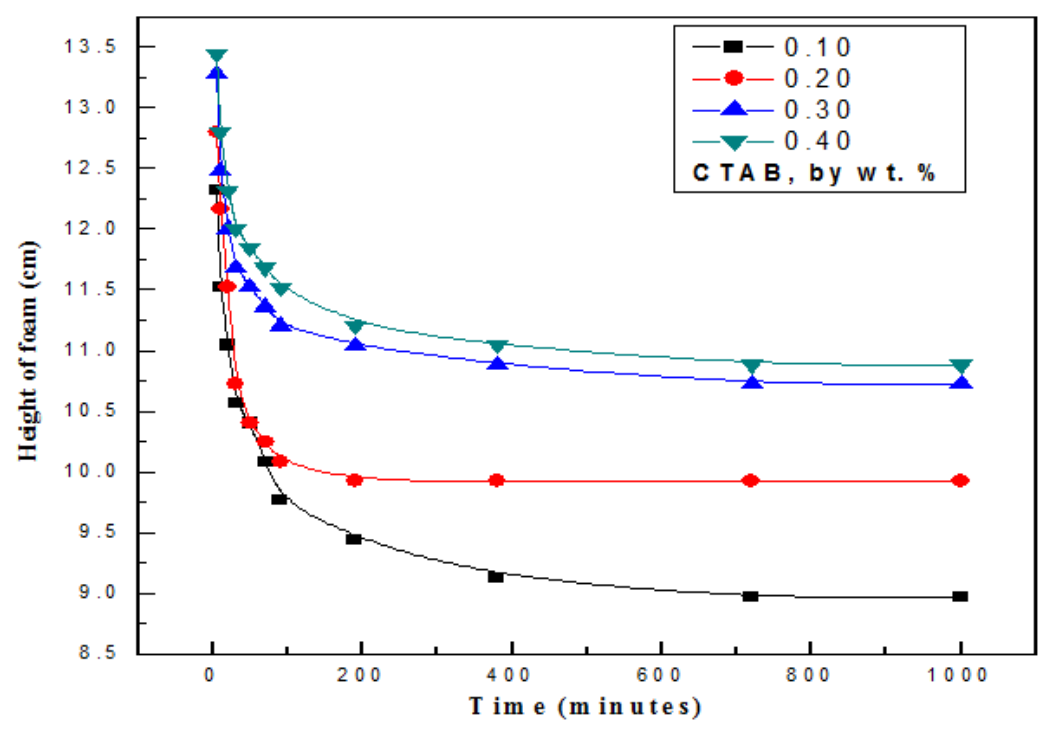

Figure 10. Effect of CTAB concentration on stability of foam ( 0.3 wt. \% HEC).

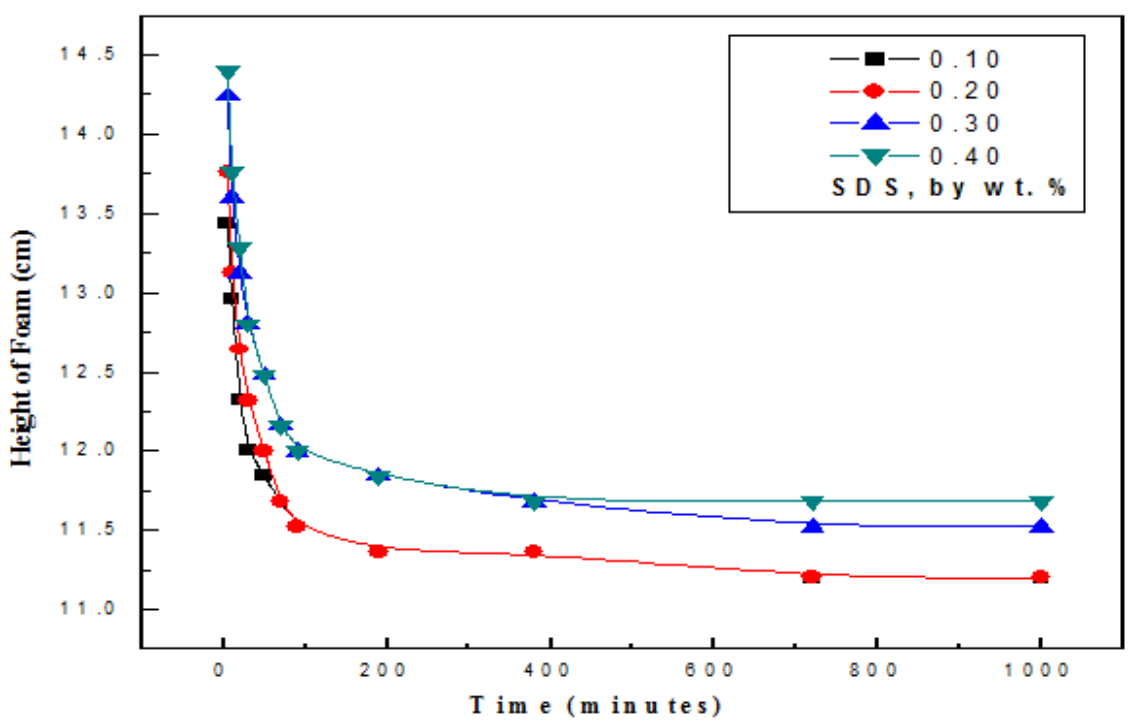

Figure 11. Effect of time on stability of foam (0.25 wt. \% HEC).

wt.\% CTAB + 0.3 wt.\% HEC, and for that of SDS is 0.3 wt.\% SDS + 0.25 wt.\% HEC (Figure 10 and Figure 11).

\subsubsection{Thermal stability}

Variation in foam quality at optimum polymer and surfactant combinations were studied for the temperature range $30{ }^{\circ} \mathrm{C}-50{ }^{\circ} \mathrm{C}$, as shown in Figure 12 and Figure 13 . The foam stability was found to decrease linearly with temperature. Degradation in foam quality is mainly due to expansion of gas within the foam at higher temperature and the change in the kinetic energy of molecules adsorbed on the surface of the bubble film (Bera et al., 2013). The increased pressure inside the bubbles combined with the randomness of surfactant molecules in the bubble film contribute significantly in breaking down the bubble film.

\subsection{Variation of apparent viscosity with surfactant concentrations at different concentrations of guar gum}

Viscosity is an important parameter for cutting transport and lubrication of drilling equipment, when determining the efficiency of drilling fluids. Variations in the viscosity of foam fluids with variation in the polymer and surfactant concentrations at various temperatures were 


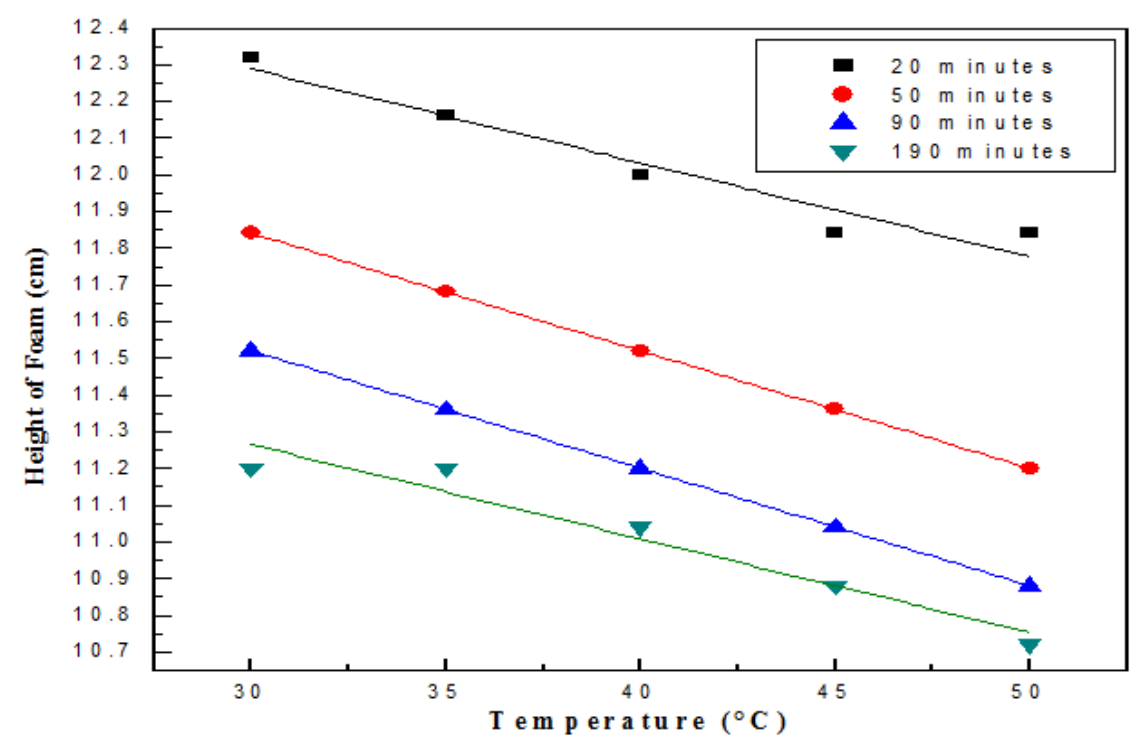

Figure 12. Thermal stability of foam as a function of temperature $(0.4 \mathrm{~g}$ CTAB $+0.3 \mathrm{~g} \mathrm{HEC})$.

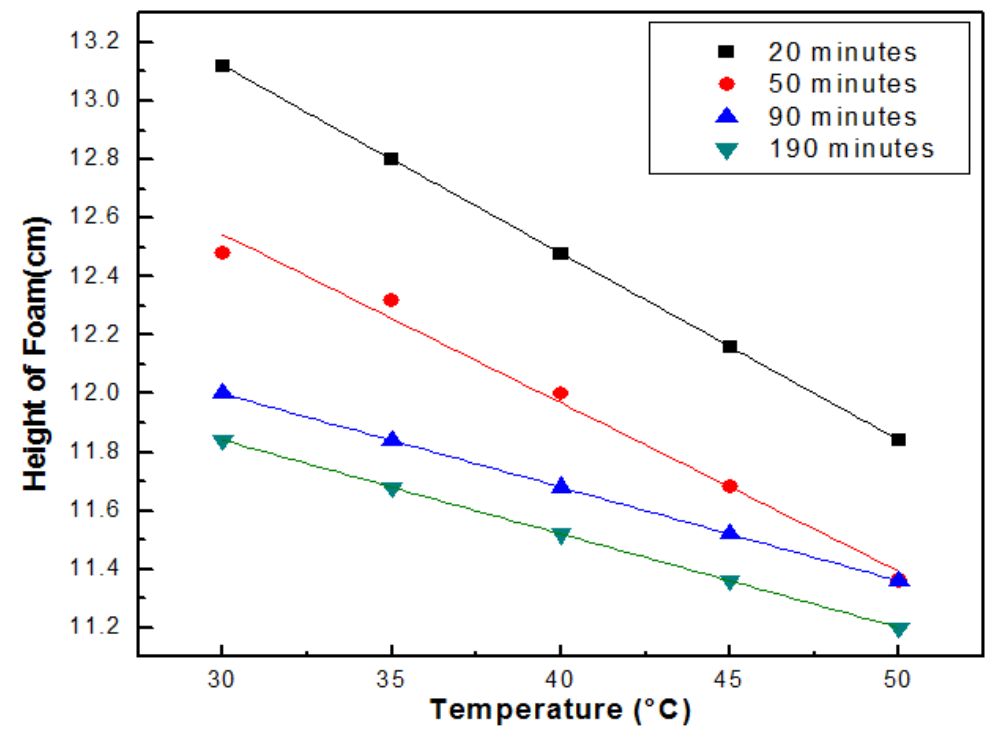

Figure 13. Stability of foam as a function of Temperature (0.3g SDS $+0.25 g$ HEC).

investigated and the results are reported in Figures 14 and 15.

It is evident from Figures 14 and 15 that, for a given concentration of surfactant, when the polymer concentration is increased the viscosity of the system increases initially, attains a maximum and then starts to decrease. For both surfactants, the viscosity is found to increase up to $0.2 \mathrm{wt}$. \% in polymer concentration, beyond which a rapid decrease in the viscosity of the foam-based drilling fluid is observed. However, for CTAB, a distinct reduction in viscosity was observed when the concentration was increased to $0.4 \%$ (see Figure 14). A small reduction in the foam viscosity was also observed (Figure 15) for SDS at $0.4 \mathrm{wt} \%$ concentration. This erratic behavior can be explained at the molecular level in terms of interactions between the surfactant and polymer molecules. According to Hoff et al. (2001) and Janiaud et al. (2007), the magnitude of the foam viscosity is primarily due to interfacial tensions between the bubble films within the foam. At lower concentrations, the polymer enhances the viscosity of the foam-based drilling fluid by contributing to the viscosity of the base fluid. The viscosity of non-ionic polymer is found to be enhanced by the addition of an anionic surfactant (Anthony and Zana, 1994; Mylonas et al., 1998; 
Winnik and Winnik, 1990). The enhanced viscosity is attributed to the adsorption of SDS molecules on the HEC polymer chains and to the conformational changes in the molecular chains that are induced due to electrostatic forces. Sometimes when a surfactant is introduced into the system, an initial decrease in the viscosity of the system is observed before it starts to increase. The decrease is attributed to the shrinking of polymer chains due to electrostatic forces between the hydrophobic and hydrophilic tails of the surfactant molecule adsorbed on the polymer chain. At low SDS concentration, surfactant and polymer molecules are dispersed in the system. As the concentration of SDS is increased more clusters of smaller sizes are formed. At low ionic strength the spacing between micelles is attributed to the mutual Columbic repulsion and their need to stick to the polymer chain. Further increase in surfactant concentration saturates the polymer chain. This behavior is observed below the critical micelle concentration (CMC) of the surfactant. At CMC, the solution contains SDS micelles which interact like bound clusters. The interfacial tension between the films of the foam bubbles is then reduced. According to Hirasaki (1985), Hohler (2005) and Karakashev (2007), at higher viscosities it becomes difficult to agitate the surfactant-polymer system.

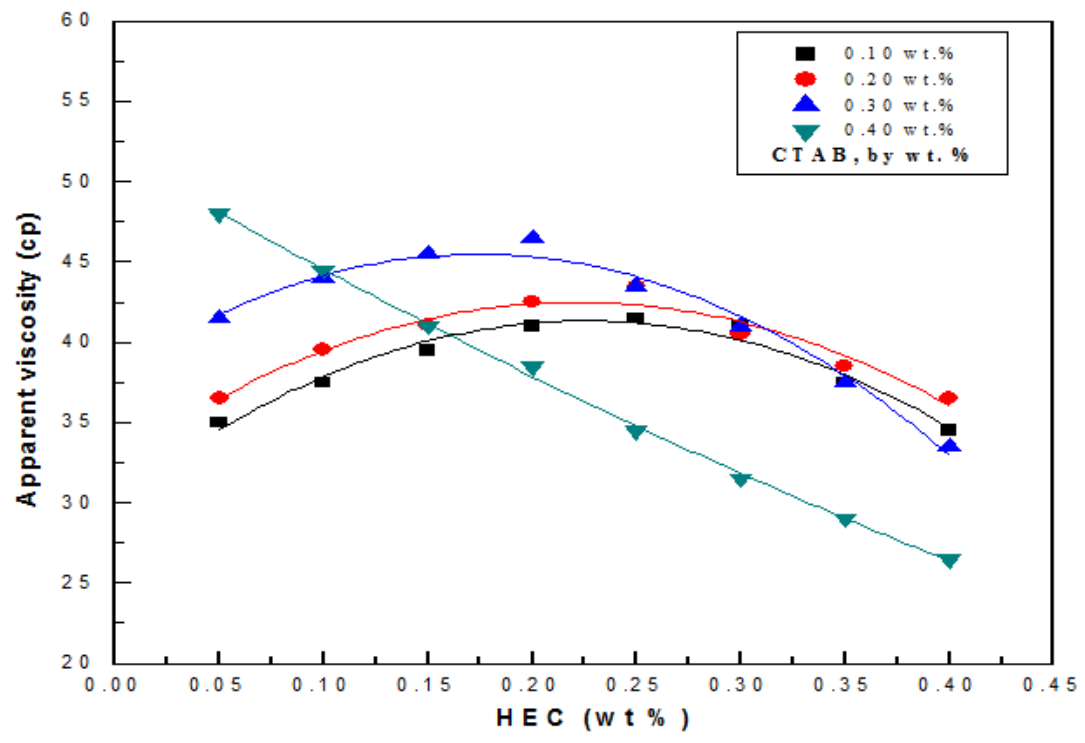

Figure 14. Variation in apparent viscosity with changing polymer concentration for given CTAB concentration.

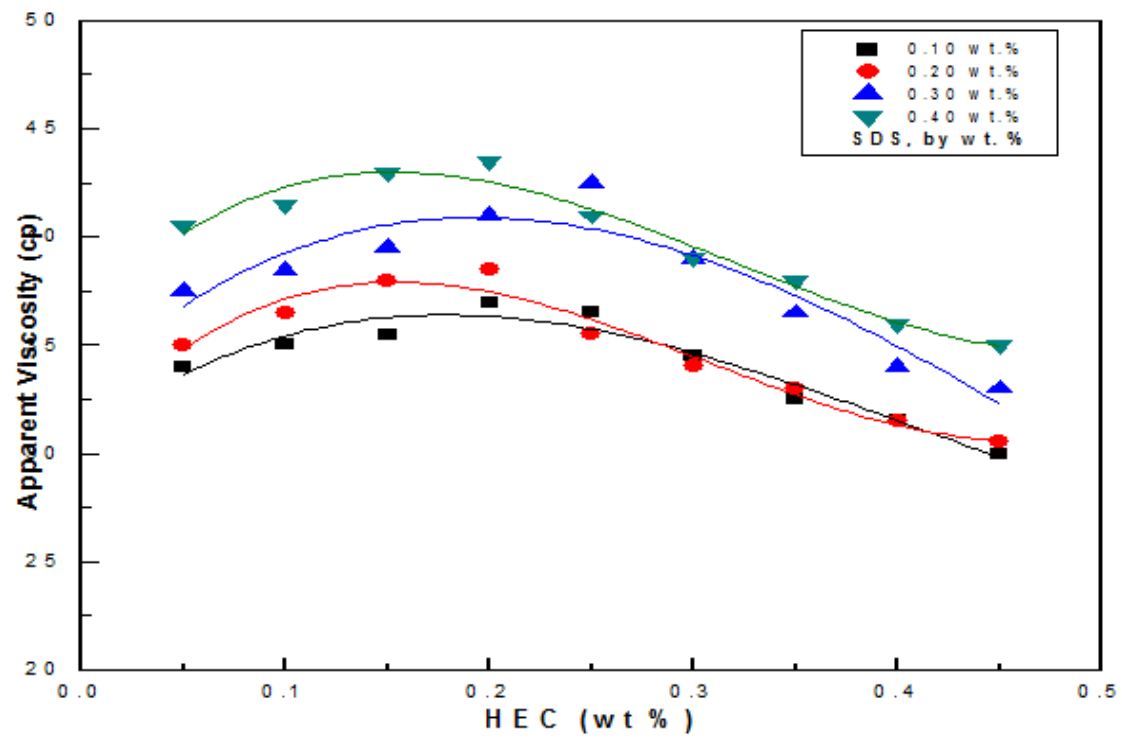

Figure 15. Variation in apparent viscosity with change in HEC concentration for a given SDS concentration. 
Also, the water transport through films is impaired, which hinders bubble coalescence. All these factors contribute to the reduction in viscosity as the polymer concentration exceeds a certain limiting value. It is observed that when the concentrations of surfactant exceed $0.3 \mathrm{wt}$. \% the viscosity of the system drops rapidly with increasing polymer concentration.

The viscosity of polymer foams with cationic surfactant is found to be less than that with SDS. According to Anthony \& Zana (1994), Mylonas et al. (1998) and Wang et al. (1995), the interaction between the cationic surfactant and nonionic polymer is less dominant as compared to that with an anionic surfactant. The suppressed interaction is due to the larger head groups present on the cationic surfactant chains, which inhibits their penetration inside the micelle structure of the cationic surfactant. This reduces the formation of surfactant-polymer clusters. Therefore a reduced interaction is observed as compared to the anionic surfactant. Furthermore, overlap of the hydration cells of polymer and surfactant head groups plays a vital role in altering the properties of the surfactant-polymer system.

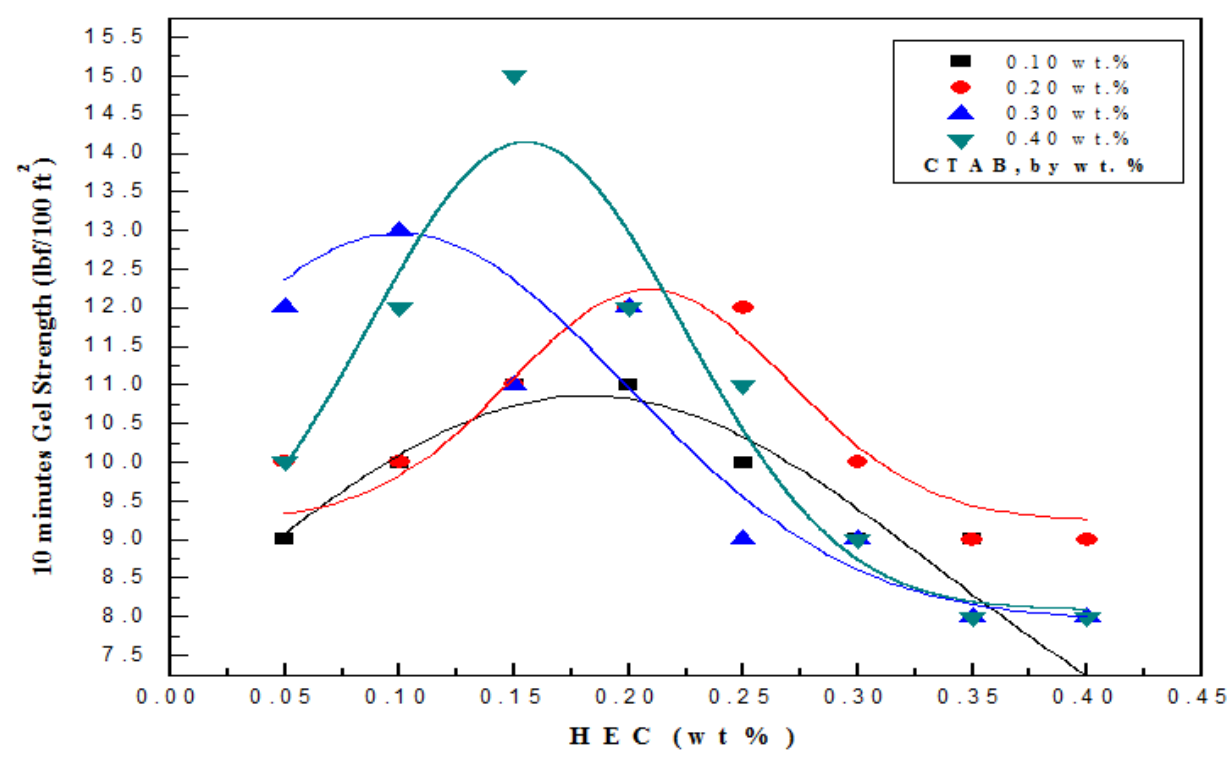

Figure 16. Gel Strength of CTAB as a function of changing polymer concentration.

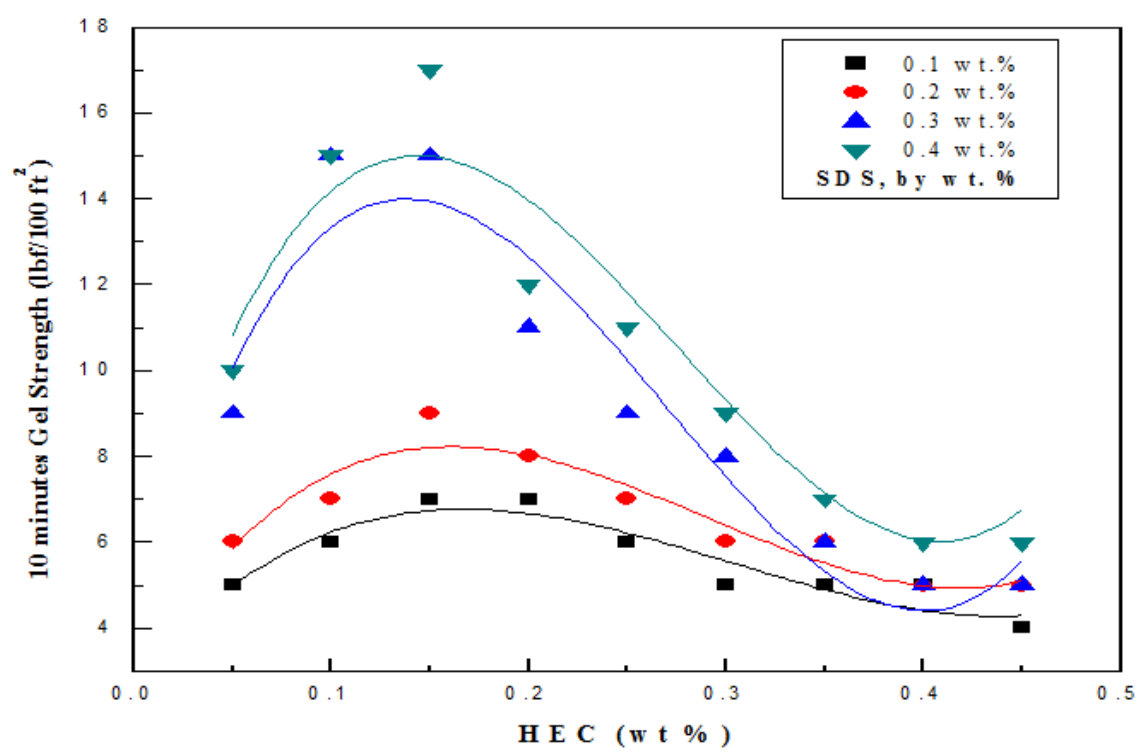

Figure 17. Gel Strength of SDS as a function of changing polymer concentration. 


\subsection{Variation of the gel strength of cationic and anionic surfactants at given polymer concentrations}

Gel strength is a property of drilling fluids which helps in the suspension of drill cutting in the fluids. 10 minutes gel strength of the foams with CTAB and SDS surfactant are plotted in Figures 16 and 17 respectively. Similar to viscosity variation, gel strength values are found to increase initially with surfactant and polymer concentrations, reach a maximum and then start to decrease. The gel strength is a function of intermolecular forces, which may be expressed in terms of interfacial tension and viscosity. In general, the higher the interfacial tension and viscosity, the higher the gel strength of the fluid will be.

From Figures 16 and 17, it can be predicted that the maximum 10-minute gel strength is observed to vary between polymer concentrations of 0.10 to $0.25 \mathrm{wt}$. \%. This rapid increase in gel strength is because of the maximum interaction between the bubbles of foam-based drilling fluids. As the polymer concentration increases above $0.2 \mathrm{wt}$. \% there is a decrease in the gel strength of the system due to saturation of polymer in the system (Edrisi, 2012; Harris, 1996; Hutchins, 2005). Therefore above this concentration no more

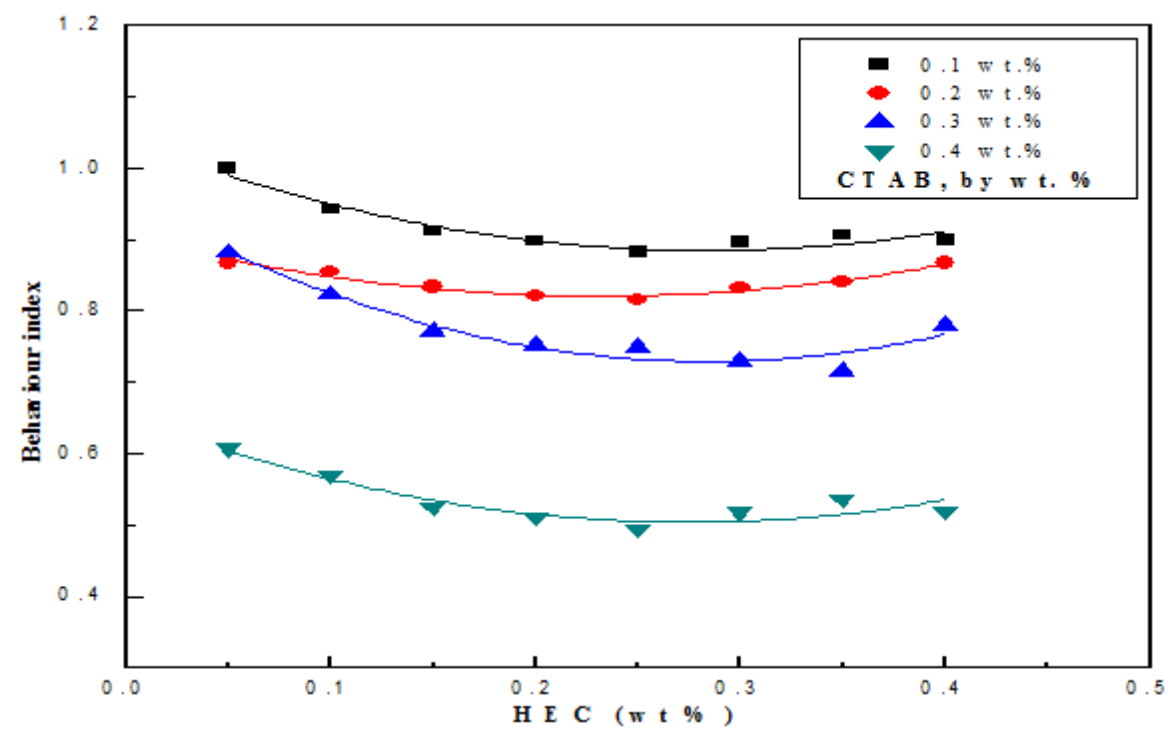

Figure 18. Behavior Index of foam for different CTAB and polymer concentration.

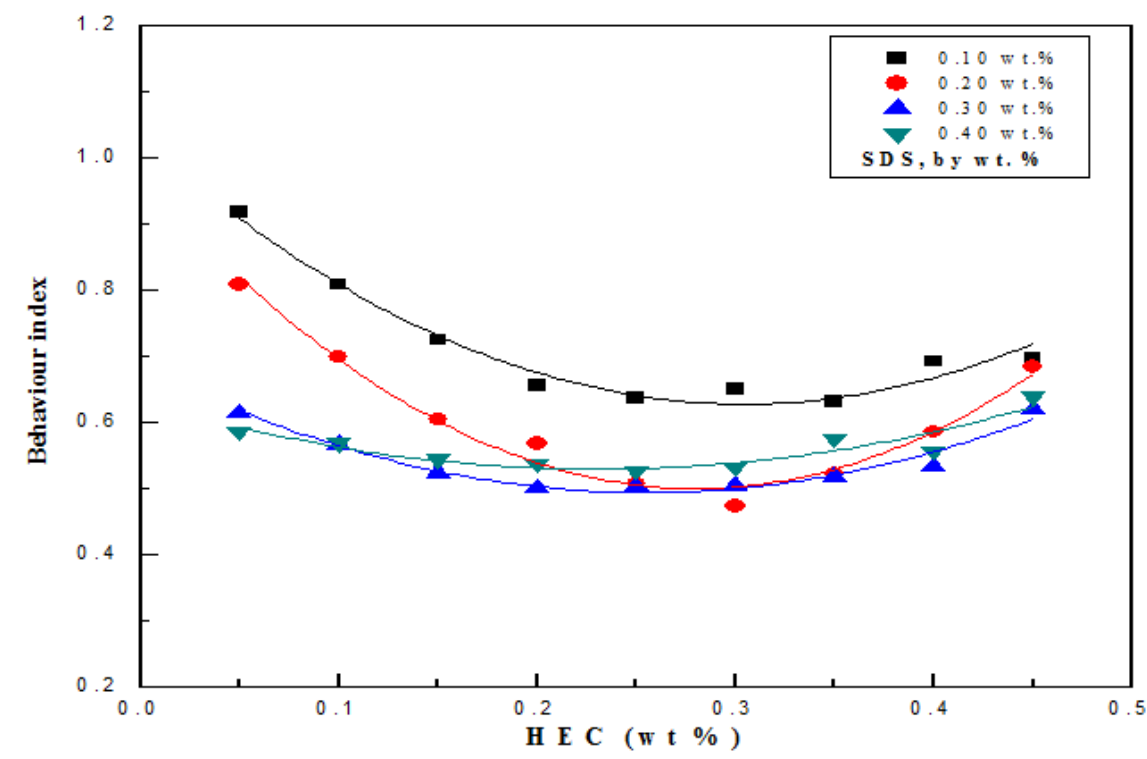

Figure 19. Behavior index of foam for different SDS and polymer concentration. 
polymer molecules can be dissolved in the foambased drilling fluid. Up to $0.2 \mathrm{wt}$. \% the polymer increases the stability of the bubble film without affecting the interaction between the foam bubbles. Above 0.2 wt. \% the polymer hinders the interaction between the bubbles, thereby affecting the gel strength of the system.

\subsection{Foam rheology}

The rheological properties of foam play an important role in determining the cutting carrying capability as well as wellbore hydraulics of foambased drilling fluids. According to Rabia (2001), the power-law model given by Equation 1 relates the shear tension $(\tau)$ with the shear rate or the velocity gradient perpendicular to the plane of shear $\left(d u / d y\right.$, in $\left.^{-1}\right)$ :

$$
\tau=K\left(\frac{d u}{d y}\right)^{n}
$$

where $\mathrm{K}$ is the flow consistency index, and $\mathrm{n}$ is the flow behavior index.

The value of behavior index indicates the degree of non-Newtonian behavior over a given shear rate range. For ' $n$ ' $=1$, the behavior of the fluid is considered to be Newtonian. As ' $n$ ' decreases the behavior of the fluid is more nonNewtonian (pseudo plastic) and the viscosity will decrease with an increase in shear rate. From Figures 18 and 19, it is evident that for all combinations the fluids show non-Newtonian or pseudo plastic behavior $(n<1)$. The degree of deviation from Newtonian behavior varies with the foam fluid compositions. According to Bonilla (2000) and Darley (2011), the decrease in the behavior index in the initial stages shows the increase in foam quality of the system at increased polymer concentrations up to a certain value. Above this concentration, the behavior of the graph is inverted, as an effect of reduction in foam quality, below which the rheological properties of base fluid becomes dominant because of phase separation.

The flow consistency index (K) is a measure of the thickness of the fluid (Rabia, 2001). An increase in the value of ' $K$ ' indicates an increase in the overall hole cleaning effectiveness of the fluid. The values of ' $\mathrm{n}$ ' and ' $\mathrm{K}$ ' are determined using Equations 2 and 3, and their variation with respect to surfactant and polymer concentrations are shown in Figures 18-21:

$$
n=3.32 \log \left(\frac{\theta_{600}}{\theta_{300}}\right)
$$

$$
K=\frac{\theta_{300}}{511^{n}}
$$

Where:

$\theta_{600}$ is the dial reading of the Fann VG viscometer at $600 \mathrm{rpm}$.

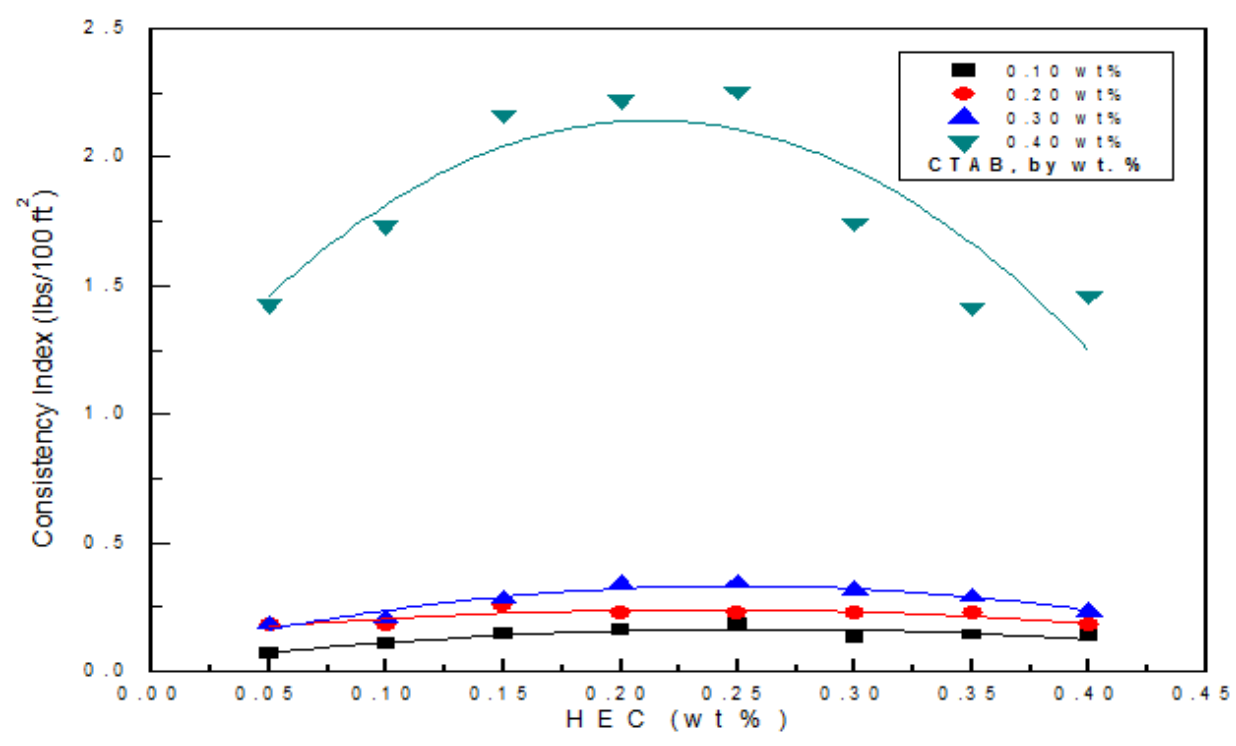

Figure 20. Consistency Index variation with changing CTAB and polymer concentration. 


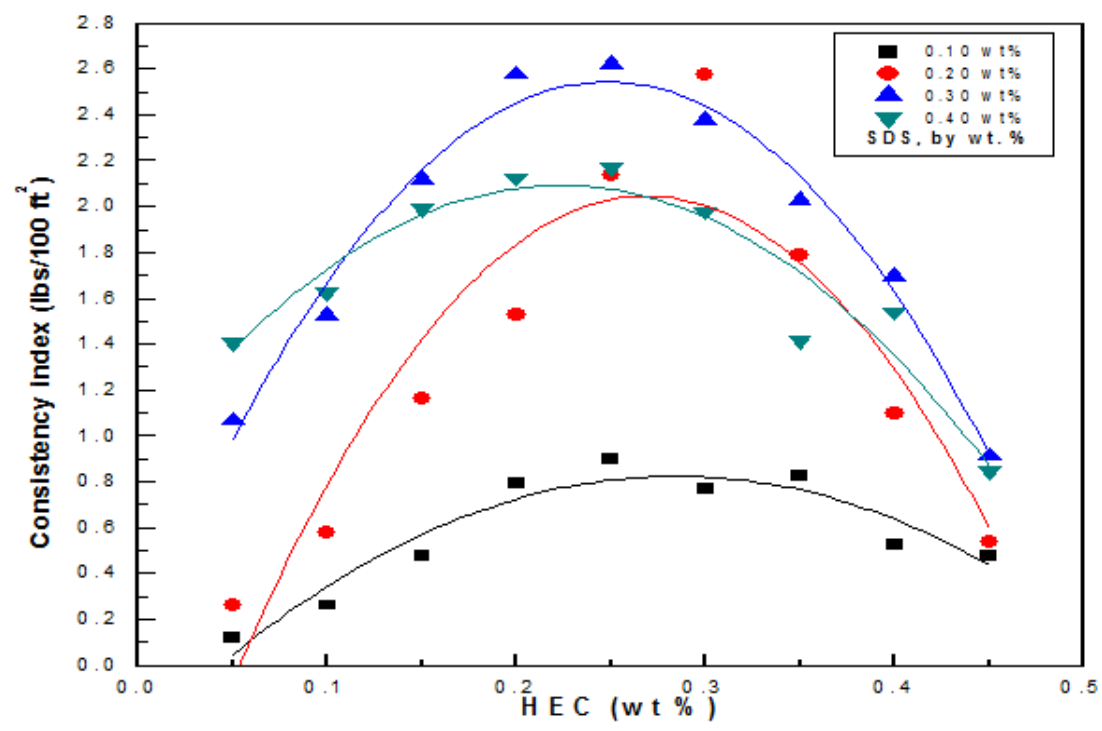

Figure 21. Consistency Index variation with changing SDS and polymer concentration.

Table 1. Different rheological parameters at optimum combinations.

\begin{tabular}{|c|c|c|c|c|c|}
\hline \multirow[t]{2}{*}{ Composition } & \multirow{2}{*}{$\begin{array}{l}\text { Plastic viscosity } \\
\text { (cp) }\end{array}$} & \multirow{2}{*}{$\begin{array}{c}\text { Apparent } \\
\text { viscosity (cp) }\end{array}$} & \multirow{2}{*}{$\begin{array}{l}\text { Yield point } \\
\mathrm{lb} / 100 \mathrm{ft}^{2}\end{array}$} & \multicolumn{2}{|c|}{$\begin{array}{l}\text { Gel strength } \\
\mathrm{lb} / 100 \mathrm{ft}^{2}\end{array}$} \\
\hline & & & & $10 \mathrm{sec}$ & $10 \mathrm{~min}$ \\
\hline $\begin{array}{c}0.3 g \text { SDS + 0.25g } \\
\text { HEC }\end{array}$ & 42.5 & 25 & 35 & 4 & 8 \\
\hline $\begin{array}{c}0.4 \text { g CTAB + } 0.3 \\
\text { g HEC }\end{array}$ & 31.5 & 19 & 25 & 5 & 9 \\
\hline
\end{tabular}

$\theta_{300}$ is the dial reading of the Fann VG viscometer at $300 \mathrm{rpm}$.

It could be observed from Figures 20 and 21 that, for the best possible combinations of CTAB and SDS, i.e. $0.4 \mathrm{~g}$ CTAB $+0.3 \mathrm{~g} \mathrm{HEC}$, and $0.3 \mathrm{~g}$ SDS $+0.25 \mathrm{~g} \mathrm{HEC}$, the highest consistency indices are obtained. So it can also be predicted that at this concentration the foam obtained is the best in terms of solid suspension and transport ability. Therefore, the hole cleaning capacity is enhanced. Table 1 summarises the main properties of the foam fluids prepared at optimum concentrations.

\section{CONCLUSIONS}

On the basis of the experimental results that were conducted to examine the stability and rheological behavior of the foam, the following results can be inferred. The prepared foam fluids showed good stability and foam quality at optimum concentrations. Anionic surfactant SDS shows better foam quality and stability compared to that of cationic surfactant CTAB. In actual field applications, anionic surfactants are also preferred over cationic ones because of their environmentally friendly nature. Variation in stability with temperature helps in determining the operating temperature window for foam-based drilling fluids. Also its variation in stability with time helps in predicting the operational duration of foam, i.e. the amount of time for which foam maintains its minimum operating qualities. For every surfactant and polymer combination there is an optimum concentration which is needed to be determined. It helps in the proper design of the hydraulics of drilling fluids. For the present study, the foam prepared at optimized condition showed a half-life more that 1000 minutes with apparent viscosity as low as $25 \mathrm{cP}$ and 10-minute gel 
strength of $8 \mathrm{lb} / 100 \mathrm{sq}-\mathrm{ft}$. Furthermore, foambased drilling fluids are found to follow the powerlaw model of fluid flow, which is pseudo plastic in nature. The values of plastic viscosity and the apparent viscosity of the foam at optimum compositions lie within the desirable range for drilling fluids (Cheng et al., 1988), hence they are applicable in downhole operating conditions. Thus, the study aims to be helpful in determining the optimum foam fluid compositions and its rheology for different downhole conditions in underbalanced drilling operations.

\section{ACKNOWLEDGEMENTS}

We greatly acknowledge NPIU and DST (No. SERB/ET-0005/2013) for financial support. Thanks are also extended to all the members associated with the project.

\section{REFERENCES}

Anthony, O.; Zana, R. Effect of Temperature on the Interactions between Neutral Polymers and a Cationic and a Nonionic Surfactant in Aqueous Solutions. Langmuir, v. 10, p. 4048-4052, 1994. http://dx.doi.org/10.1021/la00023a024

Bera, A.; Ojha, K.; Mandal A. Synergestic Effect of Mixed Surfactant on Foam Behavior and Surface Tension. Journal of surfactant and detergent, v. 16, p.621-630, 2013.

Bobo, R. A.; Barrett, H. M. Aeration of Drilling Fluids. World Oil, v. 145 (4), 1953.

Bonilla, L. F.; Shah, S. N.; et al. Experimental Investigation on the Rheology of Foams. SPE 59752, p. 1-14, 2000.

Cheng-Fa Lu; Carl A. Lukach, New Castle County, Del.; Robert R. Pas, Earls Court, United Kingdom, Carboxymethyl Guar Based Drilling Fluids. US Patent, 4,743,384, 1988.

Darley, H. C. H.; Gray, G. R.; Composition and Properties of Drilling and Completion Fluids. Gulf Professional Publishing, 2011.
Edrisi, A. R.; Gajbhiye, R. N.; Kam, S. I.; Experimental Study of Polymer-free and Polymeradded Foams for Underbalanced Drilling: Are Two Foam-Flow Regimes Still There? SPE 162712, p. 122, 2012.

Gumati, A.; Takahshi, H. Experimental Study and Modeling of Pressure Loss for Foam-Cuttings Mixture Flow in Horizontal Pipe. Journal of Hydrodynamics, v. 23, p. 431-438, 2011. http://dx.doi.org/10.1016/S1001-6058(10)60133-3

Hani, Q.; Retalic, I. Do Advanced Drilling Techniques Really Add Reserves and Enhance Recovery?. SPE 167316, p. 1-10, 2013.

Harris, P.C.; Heath, S.J. Rheology of Cross-linked Foams. SPE 28512, p. 113-116, 1996.

Herzhaft, B. Rheology of Aqueous Foams: a Literature Review of Some Experimental Works. Oil \& Gas Science and Technology, v. 54, p. 587-596, 1999. http://dx.doi.org/10.2516/ogst:1999050

Herzhaft, B.; Kakadjian, S.; Moan M. Measurement and Modelling of the Flow Behavior of Aqueous Foams Using a Recirculating Pipe Rheometer. Colloids and Surfaces A: Physico chem. Eng. Aspects, v. 263, p. 153-164, 2005. http://dx.doi.org/10.1016/j.colsurfa.2005.01.012

Hirasaki, G.J.; Lawson, J .B. Mechanisms of Foam Flow in Porous Media: Apparent Viscosity in Smooth Capillaries. SPE Journal, v. 25, p. 176-190, 1985.

Hoff, E.; Nystrom, B.; Lindman, B. PolymerSurfactant Interactions in Dilute Mixtures of a Nonionic Cellulose Derivative and an Anionic Surfactant. Langmuir, v. 17, p. 28-34, 2001. http://dx.doi.org/10.1021/la001175p

Hohler, R.; Addad, S. C. Rheology of Liquid Foam. J. Phys.: Condensed Matter, V. 17, p. 10411069, 2005.

Hutchins, R. D.; Miller, M. J. A Circulating-Foam Loop for Evaluating Foam at Conditions of Use. SPE Production \& Facilities, v. 20, p. 286-294, 2005. http://dx.doi.org/10.2118/80242-PA

Janiaud, E.; Weaire, D.; Hutzler, S. A Simple Continuum Model for the Dynamics of Quasi-Two Dimensional Foam. Colloids and Surfaces A: Physicochem. Eng. Aspects, v. 309, p. 125-131, 2007. http://dx.doi.org/10.1016/j.colsurfa.2006.10.077 
Karakashev, S. I.; Nguyen, A. V. Effect of Sodium Dodecyl Sulphate and Dodecanol Mixtures on Foam Film Drainage: Examining Influence of Surface Rheology and Intermolecular Forces. Colloids and Surfaces A: Physicochem. Eng. Aspects, v. 293, p. 229-240, 2007.

http://dx.doi.org/10.1016/j.colsurfa.2006.07.047

Li, S.; Li. Z.; et.al. Modeling of Sand Cleanout with Foam Fluid for Vertical Well. SPE Journal, v. 15, p. 805-811, 2010.

Machado, C.; Ikoku, C. U. Experimental Determination of Solids Fraction and Minimum Volumetric Requirements in Air and Gas Drilling. Journal of Petroleum Technology, p. 2645-2655, November 1982

Murai, N.; Makino, S.; Sugai, S. Interaction of Surfactants with Non-ionizable Water-Soluble Polypeptides. Journal of Colloid and Interface Science, v. 41, p. 399-406, 1972. http://dx.doi.org/10.1016/0021-9797(72)90363-3

Mylonas, Y.; Karayanni, K.; Staikos, G. Investigation of Neutral Polymer-lonic Surfactant Interactions by Fluorescence in Conjunction with Viscosity Measurements. Langmuir, v. 14, p. 63206322, 1998. http://dx.doi.org/10.1021/la980546n

Negrao, A.F.; Lage, A.C.V.M.; Cunha J.C. An Overview Of Air/Gas/Foam Drilling In Brazil, SPE Drill. \& Completion, v. 14, p. 109-114, 1999.

Ozbayoglu, E.; Kuru, E.; Miska S. A Comparative Study of Hydraulic Models for Foam Drilling. Journal of Canadian Petroleum Technology, v. 41, p. 1-10, 2002. http://dx.doi.org/10.2118/02-06-05

Rabia, H. Well Engineering and Construction. Entrac Consulting, UK, p. 197-235, 2001.

Rand, P. B.; Kraynik, A. M. Drainage of Aqueous Foams: Generation-Pressure and Cell-Size Effects. SPE Journal, v., p. 152-154, 1983.
Saintpere, S.; Herzhaft, B.; Abdoulaye, T.; Jollet, S. Rheological Properties of Aqueous Foams for Underbalanced Drilling. SPE 56633, p. 1-13, 1999.

Sanghani, V.; Ikoku, C.U. Rheology of Foam and Its Implication in Drilling and Cleanout Operations. Journal of Energy Resources Technology, p. 362371, 1983. http://dx.doi.org/10.1115/1.3230929

Tyrode, E.; Pizzino, A.; Rojasa, O.J. Foamabilty and Foam Stability at High Pressures and Temperatures. Review of Scientific Instruments, v. 74, p. 2925-2935, 2003. http://dx.doi.org/10.1063/1.1569403

Wan, L. P.; Meng, Y. F.; Li, Y.; Wang, J.; Shu, X.; Zeng, Q. The Study of the Circulation of Drilling Foam. SPE 131068, p. 1-6, 2010.

Wang, G.; Olofsson, G. Ethyl (hydroxyethy1) cellulose and Ionic Surfactants in Dilute Solution. Calorimetric and Viscosity Study of the Interaction with SDS and Some Cationic Surfactants. J Phys. Chem., v. 99, p. 5588-5596, 1995.

http://dx.doi.org/10.1021/j100015a049

Wang, M.; Du, H.; Guo, A.; Hao, R.; Hou, Z. Micro Structure Control in Ceramic Foams via Mixed Cationic/Anionic Surfactant. Materials Letters, v. 88, p. 97-100, 2012.

http://dx.doi.org/10.1016/j.matlet.2012.08.028

Weaire, D. The Rheology of Foam. Colloid \& Interface Science, v. 13, p. 171-176, 2008. http://dx.doi.org/10.1016/j.cocis.2007.11.004

Winnik, F.M.; and Winnik, M.A. The Interaction of Sodium Dodecylsulfate with (Hydroxypropyl) Cellulose. Polymer Journal, v. 22 (6), p. 482-488, 1990. http://dx.doi.org/10.1295/polymj.22.482 